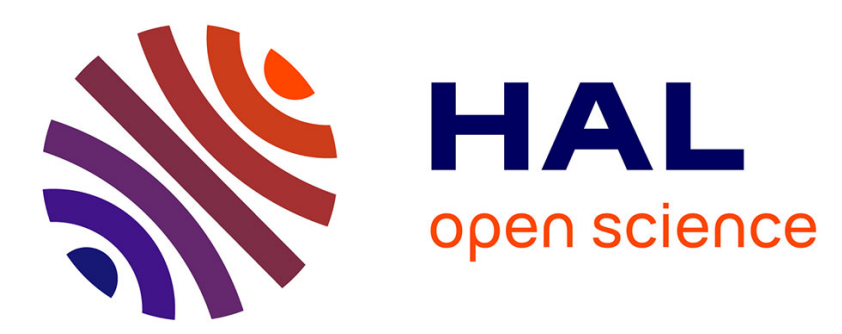

\title{
Matching habitat choice promotes species persistence under climate change
}

\author{
Felix Pellerin, Julien Cote, Elvire Bestion, Robin Aguilée
}

\section{To cite this version:}

Felix Pellerin, Julien Cote, Elvire Bestion, Robin Aguilée. Matching habitat choice promotes species persistence under climate change. Oikos, 2019, 128 (2), pp.221-234. 10.1111/oik.05309 . hal02121046

\section{HAL Id: hal-02121046 \\ https://hal.science/hal-02121046}

Submitted on 26 Nov 2020

HAL is a multi-disciplinary open access archive for the deposit and dissemination of scientific research documents, whether they are published or not. The documents may come from teaching and research institutions in France or abroad, or from public or private research centers.
L'archive ouverte pluridisciplinaire HAL, est destinée au dépôt et à la diffusion de documents scientifiques de niveau recherche, publiés ou non, émanant des établissements d'enseignement et de recherche français ou étrangers, des laboratoires publics ou privés. 
1 Matching habitat choice promotes species persistence under climate change

2 Félix Pellerin ${ }^{1 *}$, Julien Cote $^{1}$, Elvire Bestion ${ }^{1,2}$, Robin Aguilée ${ }^{1}$

3 Accepted in Oikos - Pelelrrin F, Cote J., Bestion E. \& R. Aguilée. 2019. Olkos. 128(2):

4 221-234. DOI : 10.1111/oik.05309

$5{ }^{1}$ UMR5174 (Laboratoire Evolution \& Diversité Biologique), CNRS, Université Toulouse III 6 Paul Sabatier, 118 route de Narbonne, 31062 Toulouse, France.

$8{ }^{2}$ Environment and Sustainability Institute, College of Life and Environmental Sciences, $9 \quad$ University of Exeter, Penryn, Cornwall TR10 9EZ, UK

robin.aguilee@univ-tlse3.fr

*Corresponding author:

Félix Pellerin

Université Toulouse III Paul Sabatier; UMR5174 EDB (Laboratoire Évolution \& Diversité 


\section{Abstract:}

Species may survive under contemporary climate change by either shifting their range or adapting locally to the warmer conditions. Theoretical and empirical studies recently underlined that dispersal, the central mechanism behind these responses, may depend on the match between an individuals' phenotype and local environment. Such matching habitat choice is expected to induce an adaptive gene flow, but it now remains to be studied whether this local process could promote species' responses to climate change. Here, we investigate this by developing an individual-based model including either random dispersal or temperature-dependent matching habitat choice. We monitored population composition and distribution through space and time under climate change. Relative to random dispersal, matching habitat choice induced an adaptive gene flow that lessened spatial range loss during climate warming by improving populations' viability within the range (i.e. limiting range fragmentation) and by facilitating colonization of new habitats at the cold margin. The model even predicted in some cases range contraction under random dispersal but range expansion under optimal matching habitat choice. These benefits of matching habitat choice for population persistence mostly resulted from adaptive immigration decision and were greater for populations with larger dispersal distance and higher emigration probability. We also found that environmental stochasticity resulted in suboptimal matching habitat choice, decreasing the benefits of this dispersal mode under climate change. However population persistence was still better under suboptimal matching habitat choice than under random dispersal. Our results highlight the urgent need to implement more realistic mechanisms of dispersal such as matching habitat choice into models predicting the impacts of ongoing climate change on biodiversity.

Keywords: species range shift, adaptation, dispersal, gene flow, individual-based model 
Introduction:

Contemporary climate change threatens biodiversity worldwide by impacting species persistence and distribution (Parmesan 2006, Selwood et al. 2015, Urban 2015). Species may persist under climate change through two main non-exclusive responses: by tracking suitable climatic conditions across space (geographical range shift, e.g. Hill et al. 2011, Chen et al. 2011) or by adapting to the new local climatic conditions without shifting their geographic range (populations' phenotypic shift, e.g. Boutin and Lane 2014, Merilä and Hendry 2014). Both responses are strongly influenced by dispersal (i.e. movement from the natal site to the first breeding site, or between successive breeding locations (Howard 1960)). Dispersal allows the colonization of new habitats made available by climate change and induces a gene flow affecting population's phenotypic composition. Assuming that individuals disperse with a constant probability and settle into randomly chosen habitats, gene flow is predicted to swamp local adaptation by bringing non-adapted alleles into populations (Lenormand 2002), which could compromise persistence under climate change (Pease et al. 1989, Polechová et al. 2009).

However, dispersal is increasingly recognized to be a non-random process (Bowler and Benton 2005, Edelaar et al. 2008, Clobert et al. 2009, Edelaar and Bolnick 2012, Travis et al. 2012, Lowe and McPeek 2014). The different stages of this process (i.e. departure, transience and settlement) are influenced by individual phenotype, local context and often their match (i.e. matching habitat choice). Variation in the phenotype of individuals may imply variation of fitness in specific environments which should select for inter-individual differences in emigration and immigration decisions according to their fit to local environmental conditions (Edelaar et al. 2008). Individuals are expected to move from habitats where they expect a low fitness and to settle in habitats where they expect a higher fitness, making dispersal an adaptive process. 
(Karpestam et al. 2012), fishes (Bolnick et al. 2009), birds (Dreiss et al. 2012, Camacho et al. 2016, Benkman 2017), reptiles (Cote and Clobert 2007a, Cote et al. 2008)), for different phenotypic traits matching different environmental conditions. For example, in three-spine sticklebacks (Gasterosteus aculeatus), a mark-transplant-recapture experiment showed that dispersers' preferences for lake and stream habitats depended on lake-like and stream-like morphological attributes (Bolnick et al. 2009). Under stable environmental conditions, matching habitat choice is predicted to promote adaptive gene flow compared to fitness independent dispersal (Holt 1987, Jaenike and Holt 1991, Ruxton and Rohani 1999, Armsworth and Roughgarden 2005a, 2008, Bolnick and Otto 2013, Scheiner 2016). Such adaptive gene flow acts as one of the main factors favoring population adaptation and differentiation on small spatio-temporal scales (Edelaar and Bolnick 2012, Bolnick and Otto 2013, Scheiner 2016, Edelaar et al. 2017). Despite the influence of matching habitat choice on local eco-evolutionary dynamics, there remains scope for exploring whether this individual behavioral process acting at a small spatial scale can influence species' responses to environmental conditions at larger spatial scales.

Under variable environmental conditions, matching habitat choice and ensuing adaptive gene flow may locally promote an efficient shift in mean populations' phenotypes and therefore may influence species' responses to changing conditions such as ongoing climate change. For example, in ectotherm species, physiology directly depends on external temperature and individuals are characterized by a thermal phenotype (i.e. thermal optimum and tolerance) that links their physiology and performance to temperature (Huey and Stevenson 1979). This thermal phenotype can vary within species and populations (Artacho et al. 2013, Goulet et al. 2017). Thereby, individual thermal optimum may shape individuals' movements across a landscape through the filter of phenotypic adaptations to varying temperature (Bestion et al. 2015). As climate warming is expected to increase local mismatch between individual thermal optimum and local temperature, matching habitat 
choice may make movements towards more suitable climatic conditions easier and promote an efficient shift of species geographic distribution (Edelaar and Bolnick 2012). However to our knowledge, this verbal prediction remains untested and the underlying mechanisms by which matching habitat choice may influence species' responses to climate change are still poorly understood.

Here we investigate the influence of matching habitat choice on species' responses to climate change and more precisely how very local mechanisms, here non-random individual movements, could influence species' global response to environmental change. We used an individual-based model to tackle this question to allow precise integration of such a complex process into the model. Thus, we developed a mechanistic individual-based model representing a virtual species, inspired by the biology of ectotherm species, distributed along a thermal gradient. We modeled two dispersal modes: random dispersal and matching habitat choice. We simulated different rates of climate change and followed populations' genetic composition through space and time. After quantifying the adaptiveness of gene flow under both dispersal modes, we evaluated the influence of adaptive dispersal on extinction risk at the edges of and within the spatial range, on the proportion of the geographical range within which the species goes extinct during climate change and on the time to species extinction.

\section{Methods:}

All parameters used in the model are summarized in Table 1.

\section{Environment:}

Individuals were distributed on a two dimensional landscape (i.e. grid map) constituting 1700 lines (latitudes) and 15 columns (longitudes) built as a tube to avoid edge effects. A thermal gradient representing mean annual temperatures with $0.01^{\circ} \mathrm{C}$ increment per space unit occurred along the latitudinal axis. Before climate change, temperature ranged from $19^{\circ} \mathrm{C}$ to 
$36^{\circ} \mathrm{C}$, preventing any individual from surviving at the edges of the latitudinal axis according to their initial genotypic/phenotypic values (Table 1) and therefore avoiding edge effects on the latitudinal axis. Temperature along the longitudinal axis was constant (no environmental stochasticity, though see robustness section). We assumed that all map cells could sustain a population with constant carrying capacity $\mathrm{K}$ through space and time (i.e. continuous landscape with no unsuitable habitats). We simulated two levels of climate change $\left(1^{\circ} \mathrm{C}\right.$ or $2^{\circ} \mathrm{C}$ of warming over 100 years) by uniformly increasing temperature at each location through time.

\section{Population dynamics and genetics:}

We modeled a sexual species with two life stages (juveniles and adults). Each individual was characterized by a thermal phenotype represented as a Gaussian function of survival dependency to temperature with constant variance among individuals and mean corresponding to individual thermal optimum:

$$
S(T)=e^{\frac{\left(T-T_{o p t}\right)^{2}}{2 \sigma^{2}}}
$$

with $S(T)$ being the survival probability, $T$ the local temperature, $\sigma^{2}$ the gaussian variance and $T_{\text {opt }}$ the thermal optimum. This optimum was genetically determined by 25 additive independent diploid loci with values taken from real numbers (i.e. genotypic values corresponding to phenotypic ones; the thermal optimum of each individual was thus obtained by averaging all allele values of its genotype). As a complex continuous trait, we considered that the thermal optimum was genetically determined by many independent loci with infinitesimal effects on the phenotypic trait. We arbitrarily chose to fix this number at 25 . We assume no environmental effect (i.e. no phenotypic plasticity). In each population at each time step (one time step corresponds to one year), individuals could disperse, then reproduce (adults only) and survive or die (Supplementary material Appendix A: Figure A1). 
Reproduction was independent of temperature. Each adult female produced a number of offspring taken from a Poisson distribution, with a mean fecundity of 2 . Reproducing males were randomly chosen from the same patch. For each transmitted allele, mutation occurred with a probability of $10^{-5}$ (Table 1 ). The new allele was taken from a Gaussian distribution centered on the mean parental allele value and of arbitrary variance 1.11. With such variance, $95 \%$ of new alleles were in a \pm 1 interval around the parental value. The sex of offspring was randomly chosen, resulting in a population sex-ratio of $1: 1$ at birth.

At the end of each time step, individuals died or survived. If juveniles survived they became adults and the adult stage lasted until individuals died. Survival probability depended on the match between thermal phenotype and external temperature in juveniles and adults (i.e. Gaussian function of temperature (equation (1)); Supplementary material Appendix A: Figure A1). For each phenotype, the Gaussian function was scaled such that within the temperature range of $\pm 2.4^{\circ} \mathrm{C}$ around the optimal temperature (which corresponds to the temperature range in which the non-scaled survival probability was always higher than 0.05 ), the mean survival probability was equal to 0.12 for juveniles and 0.5 for adults (Table 1 ). As observed in many species (e.g. Martin 1995 (birds), Pike et al. 2008 (reptiles), Gaillard and Yoccoz 2003 (mammals)), we considered the survival probability to be lower in juveniles than in adults. Survival was also density dependent: when current population size in a patch, $N$, exceeded carrying capacity $K$, each individual was killed with a probability $1-N / K$, so that the population size did not exceed on average the carrying capacity after the survival event. The density-dependent survival event occurred after the phenotype-dependent survival event.

We implemented two different dispersal modes, random dispersal and matching habitat choice. In the case of matching habitat choice, the departure probability of each individual depended on its expected lifetime reproductive success (LRS) (Le Galliard et al. 2008) and was exclusively driven by local thermal adaptation, that is the match between 
172 individual thermal phenotype and local temperature (i.e. survival probability without density 173 dependence called hereafter thermal survival probability; Supplementary material Appendix A: Figure A1). The lifetime reproductive success was calculated without density dependence for one year (i.e. the adult stage) for adults and for two years (i.e. the juveniles and the adult stage) for juveniles.

$$
\begin{gathered}
L R S_{\text {adult }}=\text { Fecundity }+ \text { thermal survival probability } * \text { Fecundity } \\
L R S_{\text {juvenile }}=\text { thermal survival probability } * L R S_{\text {adult }}
\end{gathered}
$$

177 with $\mathrm{LRS}_{\text {adult }}$ and $\mathrm{LRS}_{\text {juvenile }}$ being the lifetime reproductive success of adults and juveniles respectively. As we did not know the number of years an individual could live, we assumed the same reproductive success over the years for adults. $L_{R S}$ adult was therefore calculated for one year as calculating LRS over a longer period of time will not change its value. Emigration probability for each individual was calculated as 1-LRS and scaled to mimic realistic dispersal probabilities observed in nature. We considered higher dispersal in juveniles than in adults, as observed in species were natal dispersal is dominant over breeding dispersal (e.g. Greenwood and Harvey 1982). Dispersal probability thus varied from 0.3 to 0.5 for juveniles and from 0.15 to 0.35 for adults (Table 1 ). The detailed formula was as follow:

$$
\varepsilon=\varepsilon_{\text {basal }}+\left(\varepsilon_{\text {max }}-\varepsilon_{\text {basal }}\right) *\left(1-\left(\frac{L R S}{L R S_{\max }}\right)\right)
$$
with $\varepsilon$ the dispersal probability, $\varepsilon_{\text {basal }}$ the lower dispersal bound (e.g. 0.3 in juveniles), $\varepsilon_{\max }$ the upper dispersal bound (e.g. 0.5 for juveniles), LRS the lifetime reproductive success 188 (equation (2)) and $\mathrm{LRS}_{\max }$ the maximum LRS obtained when individual thermal optimum perfectly matches local temperature. Dispersers could visit all habitats on the perimeter of a circle centered on the middle of the departure habitat and of radius exactly equal to the dispersal distance and settled in the habitat that maximized their lifetime reproductive success (Supplementary material Appendix A: Figure A2). We assumed that dispersers had access to every habitat on that perimeter, including those where only a corner was on the 
circle's perimeter (i.e. as each habitat corresponded to a square on the map). Habitats at a distance from the departure habitat lower than the dispersal distance cannot be chosen to settle. Within a simulation, dispersal distance was fixed and all individuals thus dispersed at the same distance from their departure habitat. When more than one habitat maximized their lifetime reproductive success, dispersers settled randomly in one of these habitats (Supplementary material Appendix A: Figure A2).

In case of random dispersal, individuals dispersed with a constant probability $(0.3$ for juveniles and 0.15 for adults; Table 1). As the effective dispersal rate in the case of matching habitat choice was not constant over space and time, we set the random dispersal probability to be equal to the lower dispersal probability $\varepsilon_{\text {basal }}$ from the matching habitat choice scenario. We also ran simulations with random dispersal probability set to the upper dispersal probability $\varepsilon_{\max }$ from the matching habitat choice mode, allowing us to compare random dispersal with matching habitat choice scenarios for comparable dispersal probability (see robustness section). Dispersers visited all habitats on the perimeter of a circle centered on the middle of the departure habitat and of radius equal to the dispersal distance and settled in a randomly chosen habitat among these visited habitats (Supplementary material Appendix A: Figure A2). Again, all individuals thus dispersed at the same distance from their departure habitat. It allowed us to compared results obtained under matching habitat choice to the random dispersal mode without having differences in the effective dispersal distances between dispersal modes. The results we obtained by comparing simulations under both dispersal modes were thus only due to the direct effect of habitat choice in emigration and immigration decisions. The dispersal distance was fixed within simulations; we ran simulations with five dispersal distances $(2,3,4,5,6$ units on the landscape per dispersal event corresponding to a change of $0.02,0.03,0.04,0.05$ and $0.06^{\circ} \mathrm{C}$ on the thermal gradient).

To disentangle the influence of emigration from immigration in the matching habitat choice mode, we ran simulations with adaptive emigration only (dispersal probability 
depending on the match between phenotype and habitat of origin but random settlement decision) and adaptive immigration only (fixed dispersal probability but settlement decision depending on the match between phenotype and habitat visited).

\section{Simulations:}

At the beginning of simulations, we built a landscape and implemented a population of size corresponding to the carrying capacity at each location of that landscape (i.e. the entire landscape was inhabited at carrying capacity, fixed at 100 individuals at every location of the map). For each individual, the allele values of the 25 loci determining the thermal optimum were taken from a uniform distribution between 29 and $33^{\circ} \mathrm{C}$ (Table 1). The initial sex-ratio was $1: 1$ and the proportions of juveniles and adults were 0.5 each. The system evolved under stable climate for 600 years. As mutations brought new alleles into the populations, the range was not stabilized and the species would invade the landscape after a sufficient time under stable climate. We choose 600 years of stable climate before simulated climate change because it matched the minimum time needed for all phenotypes expressed from the initial distribution of genotypes (i.e. uniform distribution between $29^{\circ} \mathrm{C}$ and $33^{\circ} \mathrm{C}$ ) to be distributed on the landscape among all parameter values we tested. In the parameter set that led to the widest range size, the individuals were distributed between latitude 100 and latitude 900 corresponding to a range of temperature from 27 to $35^{\circ} \mathrm{C}$ on the grid. We also ran simulations with 800 years of stable climate and did not observe any difference in the results we obtained from those obtained with 600 years of stable climate (Supplementary material Appendix I: Figure 11-14). Then we simulated climate change for 600 years with two levels of climate change $\left(1^{\circ} \mathrm{C}\right.$ and $2^{\circ} \mathrm{C}$ of warming over 100 years) by uniformly increasing temperature at each location through time.

The model was coded in $\mathrm{C}++$ using the GNU Scientific Library for random numbers generation (Galassi et al. 2009) and outputs were analyzed using R3.3.1 (R Development Core Team 2010). 
We show the results for 20 sets of parameters values ( 2 dispersal modes * 2 levels of climate change * 5 dispersal distances), each one replicated 50 times. Simulations with adaptive emigration only and adaptive immigration only were replicated 20 times. Extra simulations for the robustness of results against various parameters of the model were replicated 20 times. The number of replication was sufficient to obtain very low standard error in our results as running simulations with 40 replicates gave the same results.

Outputs:

254

255

256

257

At the end of each time step, we calculated the mean thermal survival probability (i.e. the mean survival probability of all individuals without density dependence) through time for residents, immigrants and emigrants of each population across the range. We then calculated gene flow adaptation as the difference between immigrants' relative adaptation (i.e. difference between the mean thermal survival probability of immigrants and the mean thermal survival probability of residents of each population) and emigrants' relative adaptation (i.e. difference between the mean thermal survival probability of emigrants and the mean thermal survival probability of residents of each population).

The proportion of range loss was computed as $1-N_{t} / N_{0}$ with $N_{t}$ the number of nonempty latitudes (i.e. one individual at least was present at the given latitude) at time $t$ and $N_{0}$ the number of non-empty latitudes at time 0 (i.e. just before the start of the climate change). The extinction time was computed as the number of years of climate change needed for all populations to go extinct. When extinction did not occur during the simulation time (600 years), extinction time was arbitrarily recorded as 600 years. Range contraction was computed as $1-R_{t} / R_{0}$ with $R_{t}$ being the range size (difference between extreme occupied latitudes) at time $t$. Range fragmentation was computed as $\left(R_{t}-N_{t}\right) / R_{t}$. Finally, the local mean thermal fitness load was computed at each location and time as one minus the mean thermal survival probability of residents.

\section{Robustness:}


273 To test for the robustness of our results regarding the influence of major demographic parameters known to impact species' responses to climate change, we ran additional simulations for different parameter values of mean survival probability, fecundity, carrying capacity and dispersal probability. We varied the basal dispersal probability $\varepsilon_{\text {basal }}$ from 0.2 to 0.4 for juveniles and from 0.05 to 0.25 for adults. For simplicity, the range of variation of the emigration probability for matching habitat choice was fixed at 0.2 in all simulations. We added extra simulations of random dispersal with emigration probability of 0.5 and 0.6 for juveniles and 0.35 and 0.45 for adults, corresponding to the maximal emigration probability at which individuals could disperse in the matching habitat choice simulations. This allowed us to compare results obtained under matching habitat choice and random dispersal with similar dispersal rate. The different values for each parameter are provided in Table 1.

We also tested the influence of spatio-temporal environmental stochasticity on our because it should reduce the adaptiveness of the immigration decision in matching habitat choice mode (a right choice at time t could be wrong at time $t+1$ ). At each time step (i.e. one year), the temperature of each cell of the map was calculated as the current mean temperature of the latitude $+\mathrm{y}$, with $\mathrm{y}$ being a temperature randomly taken from a uniform distribution centered on 0 and of variance determined by the level of environmental stochasticity. The higher the environmental stochasticity is, the farther the temperature of a habitat can be from the mean temperature of the latitude. An individual that chooses a habitat that fits its phenotype at time t could therefore be maladapted the year after as the temperature changes stochastically. We ran simulations with environmental stochasticity corresponding to the temperature difference between 2 latitudes $\left(0.01^{\circ} \mathrm{C}\right), 10$ latitudes $\left(0.1^{\circ} \mathrm{C}\right)$ and 100 latitudes $\left(1^{\circ} \mathrm{C}\right)$. Parameters values are summarized in Table 1.

We also considered density dependence in matching habitat choice to test for the influence of the other factors involved in dispersal decisions. We thus included the densitydependent survival term in the lifetime reproductive success of both juveniles and adults: 


$$
\begin{aligned}
& L R S_{\text {adult with density }} \\
& \qquad \begin{array}{l}
=\text { Fecundity }+ \text { thermal survival probability } \\
\text { * density dependent survival probability } * \text { Fecundity }
\end{array} \\
& \qquad \begin{array}{l}
\text { R } S_{\text {juvenile with density }} \\
=\text { thermal survival probability } \\
* \text { density dependent survival probability } * L R S_{\text {adult }}
\end{array}
\end{aligned}
$$
the influence of mutations on the velocity of range shift.

\section{Results:}

We observed that matching habitat choice induced an adaptive gene flow under climate change (Figure 1A, Supplementary material Appendix 2: Figure B1A, B2A) while gene flow was never adaptive in the random dispersal mode. Such adaptive gene flow resulted in a higher thermal survival probability (i.e. survival probability without density dependence) of all individuals in the case of matching habitat choice than in the case of random dispersal (Figure 1B, Supplementary material Appendix 2: Figure B1B, B2B). In the matching habitat choice mode, we observed that thermal survival probability was generally higher for immigrants than for residents and emigrants excepted at time 0 where thermal survival probability was maximal for all individuals (Figure 1B and Supplementary material Appendix B: Figure B1B, B2B). In some cases, we also observed that residents' thermal survival probability was higher than emigrants' thermal survival probability (for example: Figure 1A;

314 Dispersal distance: 2 space units; Time: 200 years). In the matching habitat choice mode, 315 immigrants were therefore better adapted than residents and emigrants were therefore less adapted that residents, resulting in an adaptive gene flow. Conversely, we did not observe 
any difference in thermal survival probability between residents, immigrants and residents from the random dispersal modes (Figure 1B and Supplementary material Appendix B: Figure B1B, B2B), preventing gene flow from being adaptive.

The adaptive gene flow due to matching habitat choice decreased the probability that populations go extinct under both climate change scenarios tested and, when extinction occurred, matching habitat choice delayed it (Figure 2C, D). The spatial range loss was always lower with matching habitat choice than when individuals moved randomly (Figure 2A, B). The difference in spatial range loss between dispersal modes could be large for some sets of parameters. For example, while climate warming led to an extensive loss of $50 \%$ of the species range under a certain set of parameters of the random dispersal mode, in the matching habitat choice mode the same set of parameters led to an expansion of the spatial to random dispersal (Figure 2D).

Matching habitat choice decreased spatial range loss owing to fewer local extinctions both at the edges of the spatial range and within the spatial range compared to random dispersal. The spatial range was less contracted in the matching habitat choice mode (Figure $3 \mathrm{~A}, \mathrm{~B}$ ), because the colonizing front was moving faster (Figure 4 and Supplementary material Appendix C: Figure C1). This faster colonizing front, closer to the speed of climate change, 
was explained by individuals moving more in the direction of their shifting climatic niche when dispersal was adaptive (Figure 4 and Supplementary material Appendix C: Figure C1). It promoted species' range shift and reduced population extinction at the edges of the distribution. However for the lowest dispersal distance, the speed of the colonizing front was slower than the speed of the climate, meaning that the range was not shifting as fast as the climatic niche in the case of matching habitat choice, leading to important range size reduction. For higher dispersal distances, the speed of the colonizing front was as fast as or even faster than the speed of climate evolution in the case of matching habitat choice (Figure $4 \mathrm{C}, \mathrm{E})$. This was never the case in the random dispersal mode. The speed of the colonizing front could be faster than the speed of climate in case of matching habitat choice because of mutations. Mutations allowed new phenotypes to appear and these phenotypes, when dispersal distance was sufficient, could colonize new habitats at the cold margin of the range. Matching habitat choice promoted such colonization and we thus observed a faster colonizing front than the speed of the climate only in the case of matching habitat choice mode. When mutation rate was low, the speed of the colonizing front never overtook the speed of the climate (Supplementary material Appendix C: Figure C2).

For all parameter values, matching habitat choice also reduced local population extinctions within the spatial range (Figure 3D,E) compared to random dispersal mode. Under random dispersal mode, extinctions within the range often occurred right behind the colonizing front (Supplementary material Appendix D: Figure D1B). Local maladaptation was indeed high at this location (Supplementary material Appendix D: Figure D1C) because of the non-adaptive gene flow preventing any change in the mean populations' phenotype in response to climate change (Supplementary material Appendix D: Figure D1D). Under matching habitat choice, adaptive gene flow prevented strong maladaptation behind the colonizing front, reducing fragmentation of the range (Supplementary material Appendix D: Figure D1). 
The influence of matching habitat choice on species' response to climate change

could be explained by adaptive emigration, adaptive immigration or the combination of both. When we modeled adaptive immigration with no adaptive emigration, most results were similar to the scenario where both emigration and immigration were adaptive. Indeed, the spatial range was better maintained (Supplementary material Appendix E: Figure E1A,B), less contracted (Supplementary material Appendix E: Figure E2A,B) and - to a lesser extent - less fragmented (Supplementary material Appendix E: Figure E2C,D) and the extinction time was longer (Supplementary material Appendix E: Figure E1C,D) than under random dispersal for most parameter values. On the contrary, the results with adaptive emigration and no adaptive immigration were similar to those obtained under random dispersal (Supplementary material Appendix E: Figures E1, E2).

Dispersal distance had a strong influence on observed patterns. The higher the dispersal distance was, the higher the thermal survival probabilities of residents, of immigrants and of emigrants were, particularly in the matching habitat choice mode (Figure 1B, Supplementary material Appendix B: Figure B1B, B2B). While dispersal was always adaptive under matching habitat choice (Figure 1A, Supplementary material Appendix B: Figure B1A, B2A), dispersal distance had to be sufficiently high to maintain a high survival probability through time for all individuals (Figure 1B, Supplementary material Appendix B: Figure B1B, B2B). As dispersal distance positively influenced thermal survival probability, it also positively influenced range loss limitation, time of persistence, limitation of range contraction and range fragmentation (except under random dispersal for a warming of $2^{\circ} \mathrm{C} / 100$ years; see below) and colonization success in the two dispersal modes (Figure 2, 3, 4). However, its effect was much larger in the matching habitat choice mode than in the random dispersal mode. For example, an increase of 1 unit in dispersal distance induced a $12 \%$ reduction in range loss under random dispersal whereas the same increase allowed a shift from a range loss of $45 \%$ to a range expansion of $20 \%$ under matching habitat choice (Figure 2A; dispersal distance of 2 and 3 units). Dispersal distance also promote species 
range shift under climate change by increasing the speed of the colonizing front in both random dispersal and matching habitat choice (Figure 4). However, despite the positive influence of dispersal distance, matching habitat choice promoted species' responses to climate change compared to random dispersal even for low dispersal distances (i.e. 2 space units).

The only situation where dispersal distance did not positively influence species' response to climate change was for range contraction under random dispersal and a warming of $2^{\circ} \mathrm{C} / 100$ years (Figure 3D). In this case, fragmentation was higher for intermediate dispersal distance than for low and high dispersal distances. At low dispersal distance, the range was nearly extinct after 100 years of warming (range loss equal to 1 in case of random dispersal with a dispersal distance of 2 space unit; Figure 2B), preventing fragmentation from being high (if the range is small, extinction within the range should be rare). When dispersal distance increased, the part of the range that remained after 100 years of warming also increased (Figure 2B) allowing fragmentation to rise (Figure 3D).

In addition to dispersal distance, we explored the influence of the major demographic parameters of the model that are survival probability, fecundity, carrying capacity and emigration probability, on species' responses to climate change. We found that our conclusions held for the different parameter values we tested for. In all cases, matching habitat choice reduced range loss during climate change compared to random dispersal (Figure 5). For the majority of parameter values, matching habitat choice also extended extinction time, reduced range contraction and range fragmentation (Supplementary material Appendix F: Figure F1-F3). The higher the survival probability, fecundity, carrying capacity or emigration probability was, the lower the range loss during climate change was for both species performing matching habitat choice and random dispersal. Range loss during climate change however depended much more on survival probability and fecundity than on carrying capacity which had a very low impact (Figure 5). Interestingly, emigration probability had a greater impact on species performing matching habitat choice than on those dispersing 
randomly. For example, a 0.4 increase in juveniles emigration probability reduced range loss of 0.25 during climate change with random dispersal whereas a 0.1 increase in juveniles emigration probability reduced range loss of 0.6 with matching habitat choice (Figure 5, warming $=1^{\circ} \mathrm{C} / 100$ years).

We also tested for the influence of other factors involved in dispersal decisions such as conspecific density. We found that matching habitat choice depending on temperature and local density improved the persistence of populations (i.e. lower extinction rate (Supplementary material Appendix G: Figure $\mathrm{G} 1 \mathrm{~A}, \mathrm{~B})$ and extended time to extinction (Supplementary material Appendix G: Figure G1C,D)) compared to random dispersal, by reducing range contraction (Supplementary material Appendix G: Figure G2A,B) and range fragmentation (Supplementary material Appendix G: Figure G2C,D). Differences between results with and without the dependency of matching habitat choice on local density were well below the range of differences observed between matching habitat choice and random dispersal modes (Figure 2 and 3 versus Supplementary material Appendix G: Figure G1 and G2).

Finally, our conclusions also held for the different levels of spatio-temporal environmental stochasticity we tested for, while stochasticity led to less adaptive dispersal decisions. For all parameters values, spatial range loss for matching habitat choice during climate change was lower than, or at least equal to random dispersal (Figure 6). For the majority of parameter values, matching habitat choice also extended extinction time, reduced range contraction and range fragmentation (Supplementary material Appendix $\mathrm{H}$ : Figure $\mathrm{H} 1$ H3). In both dispersal modes, spatial range loss was positively correlated to environmental stochasticity. However, in most cases, environmental stochasticity had a stronger impact on range loss for the matching habitat choice mode than for the random dispersal mode (Figure $6 \mathrm{~A})$. Indeed, for the different dispersal distances tested, range loss under climate change in case of random dispersal was not impacted by low to moderate environmental stochasticity while range loss was impacted under matching habitat choice, confirming the negative 
451 influence of environmental stochasticity on the optimality of matching habitat choice. Under

452 very high environmental stochasticity, range loss strongly increased for both dispersal 453 modes. For this high environmental stochasticity, species went extinct in both random 454 dispersal and matching habitat choice for low dispersal distance and a warming of $2^{\circ} \mathrm{C} / 100$ 455 years (Figure $6 \mathrm{~B}$ ) such that the benefit of matching habitat choice on species range loss 456 compared to random dispersal was lost.

\section{Discussion:}

458 In this study, we demonstrated that matching habitat choice induces an adaptive gene flow 459 enhancing individuals' mean survival probability, reducing population extinction risk and improving species persistence under climate change compared to random dispersal. We investigated the influence of matching habitat choice on population dynamics and adaptation, revealing the specific mechanisms by which this local-scale dispersal strategy increases population persistence under climate change at a larger scale. Matching habitat choice (i) promotes colonization and therefore species' range expansion and (ii) reduces population extinction within the range and therefore range fragmentation.

Predictions for the probability of extinction and for the time to extinction under random dispersal and matching habitat choice greatly differed in magnitude. We even found qualitatively different predictions in some cases, where the model predicted range contraction under random dispersal while it predicted range expansion under matching habitat choice, especially for large dispersal distances (Figure 2, 3). The predicted differences for the time to extinction can be so large that the species was predicted to go extinct in 200 years in the random dispersal mode while no extinction was recorded for 600

473 years of continuing climate change in the matching habitat choice mode. Therefore, for 474 species performing matching habitat choice efficiently, this dispersal mode has to be considered when predicting populations' range shift and extinction risk. 
In our model, the benefits of matching habitat choice on species' responses to climate

change depend much more on adaptive immigration than emigration decisions (Supplementary material Appendix E: Figure E1, E2). Emigration decisions depend on individuals gathering information on local thermal conditions and assessing their phenotypic match to these conditions while immigration decisions entail a comparison of thermal conditions throughout the environment. Individuals would therefore have to visit numerous candidate habitats to choose the most suited one (Delgado et al. 2014). Species with low prospecting and dispersal abilities should thus be more at risk facing climate change as they might not be able to visit enough patches to choose habitats adaptively (Edelaar et al. 2008). However, accumulating studies evidenced fine-tuned processes underlying informed dispersal and many species may gather information on surrounding habitats before emigration (Cote and Clobert 2007b, Jacob et al. 2015a). These additional processes may reinforce the effects of adaptive immigration decisions by allowing species to orient their movements towards habitats with suitable thermal conditions.

The benefits of performing matching habitat choice compared to random dispersal may therefore depend on species ability to disperse and to gather accurate information on thermal conditions. Our results indeed show that dispersal distance and emigration probability positively influenced the benefit of adaptive gene flow - resulting from matching habitat choice - on population persistence, range fragmentation and range shift as a minimal dispersal distance is required to maintain a high survival probability through time. The minimal dispersal distance corresponded here to a distance from two to three times the distance at which the climatic niche was moving from low to high latitudes (e.g. minimal dispersal distance from 2 space units for a warming of $1^{\circ} \mathrm{C} / 100$ years). In the conditions of our model, 2 space units corresponded to $0.02^{\circ} \mathrm{C}$ variations along the gradient. In the real world, a typical annual temperature decrease with latitude is $-0.75^{\circ} \mathrm{C}$ per degree latitude (Van De Water et al. 1994). Given that one degree latitude corresponds approximately to $110 \mathrm{~km}$ around $45^{\circ}$ latitude, dispersal distances of 2 space units in our model correspond to 
distances of $2.93 \mathrm{~km}$ for temperate areas. Such distance might be achievable by many species as the mean maximum dispersal distance for species dispersing actively was found to be $9.12 \mathrm{~km}$ (Jenkins et al. 2007). We found that above this minimal dispersal distance, species could track climate change without suffering range size reduction. Overall, species with lower dispersal abilities should therefore be more at risk from climate change because they might not be able to track suitable climatic conditions and to choose habitats adaptively (Pearson 2006, Schloss et al. 2012).

We think our model could be applied to a large variety of species with good movement skills. However, as outlined above, our model is restricted to species able to perceive variation in thermal conditions and perform matching habitat choices accordingly. Matching habitat choice might therefore be easier to perform on an altitudinal than on a latitudinal axis because of the steeper thermal gradients. In mountain areas, temperature can strongly vary at local spatial scales, allowing species with low dispersal ability and/or low thermal sensitivity to detect and choose habitats with suitable microclimates. However, in lowland areas, species may also be able to perform matching habitat choice as implemented in our model. Climate change may induce important variations during a restricted period of the year (e.g. summer) while changes in mean annual temperature would appear small as in our model. These punctual variations might be enough to influence species dispersal, especially for ectotherms in which small variations near the upper physiological thermal limits induce important fitness changes (Huey et al. 2012). The pertinence of matching habitat choice should nonetheless be ascertained on a case-by-case basis.

Our conclusions may further depend on the optimality of dispersal decisions. Suboptimal emigration and immigration decisions can result from low prospecting skills and from variability in climatic conditions and environmental conditions induced by habitat fragmentation or environmental stochasticity. Indeed, in our model, environmental stochasticity led to suboptimal immigration decisions due to temporal low predictability of the climate and to increased range loss in the matching habitat choice mode. Induced 
531 suboptimal decisions however still increased species persistence under climate change in 532 comparison to random dispersal. This is in accordance with the observations of Edelaar and 533 Bolnick (2012) on population adaptation and differentiation under stable climate for random, 534 suboptimal and optimal immigration decisions. Similarly to environmental stochasticity, 535 landscape fragmentation magnifies dispersal costs and should therefore hamper the exploration of surrounding habitats reducing the optimality of dispersal decisions (Jacob et al.

537 2015b, Cote et al. 2017). Landscape fragmentation might therefore decrease the observed 538 benefits of matching habitat choice and might underpin the expected synergetic effects of climate change and fragmentation on population persistence and spatial range shift dynamics (Brook et al. 2008). This hypothesis remains to be tested. Finally, habitat choice may also become suboptimal in the presence of other major dispersal drivers. For example, intraspecific competition may influence individuals' fitness differently than local thermal

543 conditions (Paterson and Blouin-Demers 2017). Matching habitat choice may therefore depend on adaptation to both local climates and local density. In our model, the responses to climate warming were similar when matching habitat choice depended on both thermal adaptation and local density and when matching habitat choice depended on thermal adaptation only (Supplementary material Appendix G:Figure G1, G2). On top of those discussed above, we expect our conclusions to hold qualitatively for other sources of variation in the optimality of habitat choice.

Some other assumptions of our model may be critical to our results. Among these assumptions, selection occurred on survival only. Survival, but not reproductive success, depended on local temperature and density. It implies that non-adapted individuals could reproduce and transmit their genes to the next generation before dying. It should therefore slow down the adaptive process and increase the impact of non-adapted gene flow on population adaptation under random dispersal. If selection was occurring on both reproduction and survival, selection would be stronger and adaptation faster, reducing the transmission of maladapted genes to the next generation and thus the impact of maladapted 
558 individuals. As a consequence, it should limit the influence of maladaptive gene flow under 559 random dispersal that is involved in range limitation under stable climate (Kirkpatrick and 560 Barton 1997, Lenormand 2002, Bridle and Vines 2007) and may reduce the observed differences in population extinction and species' range shift between random dispersal and matching habitat choice. However, our conclusions should qualitatively hold as matching habitat choice promotes dispersal and gene flow in the direction of the moving climatic niche compared to random dispersal. Colonization of new habitats should therefore remain higher under matching habitat choice than under random dispersal.

Matching habitat choice positively influenced species' responses to climate change by limiting the mismatches between individuals' phenotypes and local environments (Figure 1A). Phenotypic plasticity may also limit such mismatches. Phenotypic plasticity has been demonstrated to influence species' responses to climate change by limiting range size reduction (Valladares et al. 2014). Recent models allowing evolution of both matching habitat choice and phenotypic plasticity demonstrated that under temporally stable climate (i.e. no change in the mean temperature in the landscape but environmental stochasticity integrated), phenotypic plasticity evolved more frequently than matching habitat choice (Scheiner 2016, Edelaar et al. 2017). However under climate change, phenotypic plasticity might delay evolutionary response in the long term, whereas matching habitat choice promotes it by inducing an adaptive gene flow (Valladares et al. 2014). Under such conditions, the benefit of phenotypic plasticity could be lower than those of matching habitat choice, promoting the evolution of the latter. On the other hand, phenotypic plasticity could limit the mismatch between phenotypes and climate until the limits of plasticity are reached. If plasticity evolved, it could allow further coping with environmental change without any evolutionary change of the traits under selection. Depending on the cost of plasticity and matching habitat choice, both mechanisms could thus evolve to facilitate species' responses to climate change. Future models could tackle this question by allowing the evolution of both 
phenotypic plasticity and matching habitat choice under a continuous period of climate change.

The influence of informed dispersal on local adaptation and population differentiation has been theoretically well-studied (Holt 1987, Armsworth and Roughgarden 2005a, b, 2008, Ravigné et al. 2009, Bolnick and Otto 2013, Holt and Barfield 2015). Others have investigated its evolution under various conditions (Travis et al. 1999, 2009, Hovestadt et al. 2010, Scheiner 2016, Edelaar et al. 2017) and its feedback effect on dispersal propensity, range limits and range expansion (Enfjäll and Leimar 2009, Kubisch et al. 2010, 2011, Bocedi et al. 2014, Poethke et al. 2016). Here we investigated the effect of a particular type of informed dispersal, matching habitat choice, on species' responses to climate change. Using a simple model with robust predictions, we showed that neglecting these mechanisms may lead to inaccurate estimates of species extinction risk and spatial range shift. Similarly, matching habitat choice should greatly affect predictions of population dynamics, evolutionary adaptation, species interactions, and changes in community composition in response to climate warming. While our model focused on the match between thermal optimum and external temperature, conclusions should be similar for any other phenotypic trait interacting with environmental variables affected by contemporary global change (e.g. hygrometry and UV intensity). We therefore recommend future research to pay more attention to matching habitat choice when studying populations' dynamics and spatial range shift to improve model predictions and management policies.

\section{Data accessibility:}

Source code of the simulations will be deposited on Dryad upon acceptance.

\section{Competing interests:}

The authors declare no competing financial interests.

\section{Authors' contributions:}


EB and JCo designed the study. All authors developed the model. FP analyzed the results and all authors discussed them. FP wrote the first draft of the manuscript and all authors contributed substantially to revisions.

\section{Funding:}

613 F. P. was supported by a PhD fellowship from the French "Ministère de la Recherche et de la 614 Technologie". JCo was supported by an ANR-12-JSV7-0004-01 and by the ERA-Net 615 BiodivERsA, with the national funder ONEMA, part of the 2012-2013 BiodivERsA call for 616 research proposals. EB was supported by a young researchers' award from the Bettencourt617 Schueller foundation. This work was supported by the French Laboratory of Excellence 618 project "TULIP" (ANR-10-LABX-41). This work was performed using the cluster EDB-Calc 619 (which includes software developed by the Rocks(r) Cluster Group at the San Diego 620 Supercomputer Center, University of California) of the laboratory "Evolution et Diversité 621 Biologique".

\section{Acknowledgements:}

623 We are grateful to S. Meylan, O. Ronce and E. Fronhofer for comments and suggestions on 624 the models and results. We thank Pim Edelaar, Justin Travis and reviewers for their useful 625 comments on the manuscript. We thank Aïsha Bruendl for editing the manuscript. We thank 626 P. Solbès for support on the EDB-Calc system. 


\section{References:}

629

630

631

632

633

634

635

636

637

638

639

640

641

642

643

644

645

646

647

648

649

650

651

652

653

654

655

656

657

658

659

660

661

662

Armsworth, P. R. and Roughgarden, J. E. 2005a. The impact of directed versus random movement on population dynamics and biodiversity patterns. - Am. Nat. 165: 449-465.

Armsworth, P. R. and Roughgarden, J. E. 2005b. Disturbance induces the contrasting evolution of reinforcement and dispersiveness in directed and random movers. - Evolution 59: 20832096.

Armsworth, P. R. and Roughgarden, J. E. 2008. The structure of clines with fitness-dependent dispersal. - Am. Nat. 172: 648-657.

Artacho, P. et al. 2013. Interindividual variation in thermal sensitivity of maximal sprint speed, thermal behavior, and resting metabolic rate in a lizard. - Physiol. Biochem. Zool. 86: 458469.

Benkman, C. W. 2017. Matching habitat choice in nomadic crossbills appears most pronounced when food is most limiting. - Evolution 71: 778-785.

Bestion, E. et al. 2015. Dispersal response to climate change: scaling down to intraspecific variation. Ecol. Lett. 18: 1226-1233.

Bocedi, G. et al. 2014. Mechanistic modelling of animal dispersal offers new insights into range expansion dynamics across fragmented landscapes. - Ecography 37: 1240-1253.

Bolnick, D. I. and Otto, S. P. 2013. The magnitude of local adaptation under genotype-dependent dispersal. - Ecol. Evol. 3: 4722-4735.

Bolnick, D. I. et al. 2009. Phenotype-dependent native habitat preference facilitates divergence between parapatric lake and stream stickleback. - Evolution 63: 2004-2016.

Boutin, S. and Lane, J. E. 2014. Climate change and mammals: evolutionary versus plastic responses. Evol. Appl. 7: 29-41.

Bowler, D. E. and Benton, T. G. 2005. Causes and consequences of animal dispersal strategies: relating individual behaviour to spatial dynamics. - Biol. Rev. 80: 205-225.

Bridle, J. R. and Vines, T. H. 2007. Limits to evolution at range margins: when and why does adaptation fail? - Trends Ecol. Evol. 22: 140-147.

Brook, B. W. et al. 2008. Synergies among extinction drivers under global change. - Trends Ecol. Evol. 23: 453-460.

Camacho, C. et al. 2016. Natal habitat imprinting counteracts the diversifying effects of phenotypedependent dispersal in a spatially structured population. - BMC Evol. Biol. 16: 158-167.

Chen, I.-C. et al. 2011. Rapid range shifts of species associated with high levels of climate warming. Science 333: 1024-1026.

Clobert, J. et al. 2009. Informed dispersal, heterogeneity in animal dispersal syndromes and the dynamics of spatially structured populations. - Ecol. Lett. 12: 197-209. 
Cote, J. and Clobert, J. 2007a. Social personalities influence natal dispersal in a lizard. - Proc. R. Soc. B Biol. Sci. 274: 383-390.

Cote, J. and Clobert, J. 2007b. Social information and emigration: lessons from immigrants. - Ecol. Lett. 10: 411-417.

Cote, J. et al. 2008. Social personality trait and fitness. - Proc. R. Soc. B Biol. Sci. 275: 2851-2858.

Cote, J. et al. 2017. Evolution of dispersal strategies and dispersal syndromes in fragmented landscapes. - Ecography 40: 56-73.

Delgado, M. M. et al. 2014. Prospecting and dispersal: their eco-evolutionary dynamics and implications for population patterns. - Proc. R. Soc. Lond. B Biol. Sci. 281:2013-2851.

Dreiss, A. N. et al. 2012. Local adaptation and matching habitat choice in female barn owls with respect to melanic coloration. - J. Evol. Biol. 25: 103-114.

Edelaar, P. and Bolnick, D. I. 2012. Non-random gene flow: an underappreciated force in evolution and ecology. - Trends Ecol. Evol. 27: 659-665.

Edelaar, P. et al. 2008. Matching habitat choice causes directed gene flow: a neglected dimension in evolution and ecology. - Evolution 62: 2462-2472.

Edelaar, P. et al. 2017. Should I change or should I go? Phenotypic plasticity and matching habitat choice in the adaptation to environmental heterogeneity. - Am. Nat. 190: 506-520.

Enfjäll, K. and Leimar, O. 2009. The evolution of dispersal - the importance of information about population density and habitat characteristics. - Oikos 118: 291-299.

Gaillard, J.-M. and Yoccoz, N. G. 2003. Temporal variation in survival of mammals: A case of environmental canalization? - Ecology 84: 3294-3306.

Galassi, M. et al. 2009. GNU Scientific Library Reference Manual - 3rd Ed.

Goulet, C. T. et al. 2017. Repeatability and correlation of physiological traits: Do ectotherms have a "thermal type"? - Ecol. Evol. 7: 710-719.

Greenwood, P. J. and Harvey, P. H. 1982. The natal and breeding dispersal of birds. - Annu. Rev. Ecol. Syst. 13: 1-21.

Hill, J. K. et al. 2011. Climate change and evolutionary adaptations at species' range margins. - Annu. Rev. Entomol. 56: 143-159.

Holt, R. D. 1987. Population dynamics and evolutionary processes: the manifold roles of habitat selection. - Evol. Ecol. 1: 331-347.

Holt, R. D. and Barfield, M. 2015. The influence of imperfect matching habitat choice on evolution in source-sink environments. - Evol. Ecol. 29: 887-904.

Hovestadt, T. et al. 2010. Information processing in models for density-dependent emigration: A comparison. - Ecol. Model. 221: 405-410.

Howard, W. E. 1960. Innate and environmental dispersal of individual vertebrates. - Am. Nat. 63: 152-161. 
Huey, R. B. and Stevenson, R. 1979. Integrating thermal physiology and ecology of ectotherms: a discussion of approaches. - Am. Zool. 19: 357-366.

Huey, R. B. et al. 2012. Predicting organismal vulnerability to climate warming: roles of behaviour, physiology and adaptation. - Philos. Trans. R. Soc. B Biol. Sci. 367: 1665-1679.

Jacob, S. et al. 2015a. Social information from immigrants: multiple immigrant-based sources of information for dispersal decisions in a ciliate. - J. Anim. Ecol. 84: 1373-1383.

Jacob, S. et al. 2015b. Habitat matching and spatial heterogeneity of phenotypes: implications for metapopulation and metacommunity functioning. - Evol. Ecol. 29: 851-871.

Jaenike, J. and Holt, R. D. 1991. Genetic variation for habitat preference: evidence and explanations. Am. Nat. 137: S67-S90.

Jenkins, D. G. et al. 2007. Does size matter for dispersal distance? - Glob. Ecol. Biogeogr. 16: 415-425.

Karpestam, E. et al. 2012. Matching habitat choice by experimentally mismatched phenotypes. - Evol. Ecol. 26: 893-907.

Kirkpatrick, M. and Barton, N. H. 1997. Evolution of a species' range. - Am. Nat. 150: 1-23.

Kubisch, A. et al. 2010. On the elasticity of range limits during periods of expansion. - Ecology 91: 3094-3099.

Kubisch, A. et al. 2011. Density-dependent dispersal and the formation of range borders. - Ecography 34: 1002-1008.

Le Galliard, J.-F. et al. 2008. Lifetime and intergenerational fitness consequences of harmful male interactions for female lizards. - Ecology 89: 56-64.

Lenormand, T. 2002. Gene flow and the limits to natural selection. - Trends Ecol. Evol. 17: 183-189.

Lowe, W. H. and McPeek, M. A. 2014. Is dispersal neutral? - Trends Ecol. Evol. 29: 444-450.

Martin, K. 1995. Patterns and Mechanisms for Age-dependent Reproduction and Survival in Birds. Am. Zool. 35: 340-348.

Merilä, J. and Hendry, A. P. 2014. Climate change, adaptation, and phenotypic plasticity: the problem and the evidence. - Evol. Appl. 7: 1-14.

Parmesan, C. 2006. Ecological and evolutionary responses to recent climate change. - Annu. Rev. Ecol. Evol. Syst. 37: 637-669.

Paterson, J. E. and Blouin-Demers, G. 2017. Density-dependent habitat selection predicts fitness and abundance in a small lizard. - Oikos in press.

Pearson, R. G. 2006. Climate change and the migration capacity of species. - Trends Ecol. Evol. 21: 111-113.

Pease, C. M. et al. 1989. A model of population growth, dispersal and evolution in a changing environment. - Ecology 70: 1657-1664. 
Pike, D. A. et al. 2008. Estimated survival rates of Uncatchable animals: The myth of juvenile mortality in reptiles. - Ecology 89: 607-611.

Poethke, H. J. et al. 2016. The Adequate Use of Limited Information in Dispersal Decisions. - Am. Nat. 187: 136-142.

Polechová, J. et al. 2009. Species' range: adaptation in space and time. - Am. Nat. 174: 186-204.

R Development Core Team 2010. R: A language and environment for statistical computing. - R Foundation for Statistical Computing.

Ravigné, V. et al. 2009. Live where you thrive: joint evolution of habitat choice and local adaptation facilitates specialization and promotes diversity. - Am. Nat. 174: 141-169.

Ruxton, G. D. and Rohani, P. 1999. Fitness-dependent dispersal in metapopulations and its consequences for persistence and synchrony. - J. Anim. Ecol. 68: 530-539.

Scheiner, S. M. 2016. Habitat choice and temporal variation alter the balance between adaptation by genetic differentiation, a jack-of-all-trades strategy, and phenotypic plasticity. - Am. Nat. 187: 633-646.

Schloss, C. A. et al. 2012. Dispersal will limit ability of mammals to track climate change in the Western Hemisphere. - Proc. Natl. Acad. Sci. 109: 8606-8611.

Selwood, K. E. et al. 2015. The effects of climate change and land-use change on demographic rates and population viability. - Biol. Rev. 90: 837-853.

Travis, J. M. J. et al. 1999. The evolution of density-dependent dispersal. - Proc. R. Soc. Lond. B Biol. Sci. 266: 1837-1842.

Travis, J. M. et al. 2009. Accelerating invasion rates result from the evolution of density-dependent dispersal. - J. Theor. Biol. 259: 151-158.

Travis, J. M. et al. 2012. Modelling dispersal: an eco-evolutionary framework incorporating emigration, movement, settlement behaviour and the multiple costs involved. - Methods Ecol. Evol. 3: 628-641.

Urban, M. C. 2015. Accelerating extinction risk from climate change. - Science 348: 571-573.

Valladares, F. et al. 2014. The effects of phenotypic plasticity and local adaptation on forecasts of species range shifts under climate change. - Ecol. Lett. 17: 1351-1364.

Van De Water, P. K. et al. 1994. Trends in Stomatal Density and ${ }^{13 \$} \mathrm{C} /{ }^{12 \$} \mathrm{C}$ Ratios of Pinus flexilis Needles During Last Glacial-Interglacial Cycle. - Science 264: 239-243. 
Table caption:

Table 1: Summary of the model parameters and their values in the main simulations and in extra simulations performed for robustness analyses.

\section{Figures captions:}

Figure 1: Adaptiveness of gene flows and thermal survival probability. Adaptiveness of the gene flow $(\mathbf{A})$ and the thermal survival probability of emigrants, immigrants and residents (B) through time for different dispersal distances in case of matching habitat choice (circles and solid lines $(\mathbf{A})$ and blue bars $(\mathbf{B})$ ) or random dispersal (triangles and dashed lines $(\mathbf{A})$, and green bars (B)). Results were obtained under a climate change scenario of $1^{\circ} \mathrm{C}$ of warming over 100 years. A) Thermal adaptiveness of total gene flow through time for different dispersal distances for the matching habitat choice (black) and random dispersal (white) scenarios (see methods for details). B) Thermal survival probability of emigrants (dark blue for matching habitat choice, dark green for random dispersal), immigrants (medium blue for matching habitat choice, medium green for random dispersal) and residents (light blue for matching habitat choice, light green for random dispersal) through time for different dispersal distances in case of matching habitat choice (blue bars) and random dispersal (green bars). Means ( $\pm S D$ ) over 50 simulations are shown.

Figure 2: Consequences of adaptive gene flow on species responses to climate change. Proportion of spatial range loss $(\mathbf{A}, \mathbf{B})$ and extinction time $(\mathbf{C}, \mathbf{D})$ depending on dispersal distance in case of matching habitat choice (black bars) or random dispersal (white bars) and for two climate change scenarios (scenario $\mathbf{A}, \mathbf{C}: 1^{\circ} \mathrm{C} / 100$ years, scenario $\mathbf{B}, \mathbf{D}$ : $2^{\circ} \mathrm{C} / 100$ years). Spatial range loss was measured after 200 years of warming for scenario $\mathbf{A}$ and after 100 years of warming for scenario $\mathbf{B}$. When the species persisted until the end of simulations (600 years), the extinction time was indicated as 600 years. Means ( \pm SD) over 50 simulations are shown. 
Figure 3: Spatial range contraction and fragmentation. Proportion of spatial range contraction $(\mathbf{A}, \mathbf{B})$ and spatial range fragmentation $(\mathbf{C}, \mathbf{D})$ depending on dispersal distance in case of matching habitat choice (black bars) or random dispersal (white bars) and for two climate change scenarios (scenario A,C: $1^{\circ} \mathrm{C} / 100$ years, scenario B,D: $2^{\circ} \mathrm{C} / 100$ years). Spatial range contraction was measured after 200 years of warming for scenario $\mathbf{A}$ and after 100 years of warming for scenario B. Spatial range fragmentation was measured between 0 and 200 years of warming for scenario $\mathbf{C}$ and between 0 and 100 years of warming for scenario D. Means $( \pm \mathrm{SD})$ over 50 simulations are shown.

Figure 4: Colonization dynamics. Mean speed dynamics of colonizing front though time in case of matching habitat choice (black solid line) or random dispersal (light gray solid line) and for two climate change scenarios (scenario A,C,E: $1^{\circ} \mathrm{C} / 100$ years, scenario $\mathbf{B}, \mathbf{D}, \mathbf{F}$ : $2^{\circ} \mathrm{C} / 100$ years). To keep up with the pace of climate change, the front speed should be as high as the dashed line. Three different dispersal distances were tested: 2 space units (scenarios A,B), 3 space units (scenarios C,D) and 4 space units (scenarios E,F). Mean curves over 50 simulations are shown.

Figure 5: Influence of demographic parameters on spatial range loss during climate change. Proportion of spatial range loss depending on survival probability $(\mathbf{A}, \mathbf{B})$, fecundity (C,D), carrying capacity $(\mathbf{E}, \mathbf{F})$ and emigration probability $(\mathbf{G}, \mathbf{H})$ in case of matching habitat choice (open circle, solid line) or random dispersal (open triangle, dashed line) and for two climate change scenarios (scenario $\mathbf{A}, \mathbf{C}, \mathbf{E}, \mathbf{G}: 1^{\circ} \mathrm{C} / 100$ years, scenario $\mathbf{B}, \mathbf{D}, \mathbf{F}, \mathbf{H}: 2^{\circ} \mathrm{C} / 100$ years). Spatial range loss was measured after 200 years of warming for scenario A,C,E,G and after 100 years of warming for scenario B,D,F,H. In A,B) only juvenile survival probability was represented but it was associated with adult survival probability ( 0.5 for juvenile survival probability of 0.12 and 0.6 for juvenile survival probability of 0.25 ). In $\mathbf{G}, \mathbf{H}$ the $\mathbf{x}$ axis represented the basal juvenile emigration probability. It was associated with an adult emigration probability $(0.05$ for the basal juvenile emigration probability of $0.2,0.15$ for the basal juvenile emigration probability of $0.4,0.25$ for the basal juvenile emigration probability 
of $0.4,0.35$ for the basal juvenile emigration probability of 0.5 and 0.45 for the basal juvenile emigration probability of 0.6 ). In case of random dispersal emigration probabilities for juveniles and adults was fixed whereas emigration probabilities could vary in case of matching habitat choice (from 0.2 to 0.4 and 0.05 to 0.25 for juveniles and adults respectively for the basal juvenile emigration probability of 0.2 ; from 0.3 to 0.5 and 0.15 to 0.35 for juveniles and adults respectively for the basal juvenile emigration probability of 0.3 ; from 0.4 to 0.6 for juveniles and adults respectively for the basal juvenile emigration probability of 0.4 ). Means $( \pm S D$ ) over 50 (parameter values of main simulations (Table A1)) or 20 (parameter values of extra simulations (Table A1)) simulations are shown.

\section{Figure 6: Influence of environmental stochasticity on spatial range loss during climate}

change. Proportion of spatial range loss depending on environmental stochasticity in case of matching habitat choice (circles and solid lines) or random dispersal (triangles and dashed lines) for different dispersal distances (A,B: 3 space units; C,D: 4 space units; E,F: 5 space units) and for two climate change scenarios (scenario A,C,E: $1^{\circ} \mathrm{C} / 100$ years, scenario B,D,F: $2^{\circ} \mathrm{C} / 100$ years). The level of environmental stochasticity determined how much the temperature of habitats on a given latitude could vary around the current mean temperature of this latitude (see methods section for details). Spatial range loss was measured after 200 years of warming for scenario A,C,E and after 100 years of warming for scenario B,D,F. Means $( \pm S D$ ) over 50 (parameter values of main simulations (Table A1)) or 20 (parameter values of extra simulations (Table A1)) simulations are shown.

\section{Table:}

\begin{tabular}{|l|l|l|}
\hline Parameters & Main simulations & Extra simulations \\
\hline Fecundity & 2 & 1 and 3 \\
\hline Mean juvenile survival probability & 0.12 & 0.25 \\
\hline Mean adult survival probability & 0.5 & 0.6 \\
\hline Carrying capacity K & 100 & 50 and 150 \\
\hline $\begin{array}{l}\text { Juvenile emigration probability range for } \\
\text { matching habitat choice }\left(\varepsilon_{\text {basal }} \text { and } \varepsilon_{\max } \text { for }\right.\end{array}$ & $0.3-0.5$ & $0.2-0.4$ and $0.4-0.6$ \\
\hline
\end{tabular}




\begin{tabular}{|l|l|l|}
\hline juveniles) & & \\
\hline $\begin{array}{l}\text { Adult emigration probability range for } \\
\text { matching habitat choice }\left(\varepsilon_{\text {basal }} \text { and } \varepsilon_{\text {max }} \text { for }\right. \\
\text { adults) }\end{array}$ & $0.15-0.35$ & $0.05-0.25$ and $0.25-0.45$ \\
\hline $\begin{array}{l}\text { Juvenile emigration probability for random } \\
\text { dispersal }\end{array}$ & 0.3 & $0.2,0.4,0.5$ and 0.6 \\
\hline $\begin{array}{l}\text { Adult emigration probability for random } \\
\text { dispersal }\end{array}$ & 0.15 & $0.05,0.25,0.35$ and 0.45 \\
\hline Dispersal distance & $2,3,4,5$ and 6 & 3,4 and 5 \\
\hline Mutation probability & $10^{-5}$ & $10^{-7}$ \\
\hline Loci number & 25 & 25 \\
\hline Initial allele range & $29-33^{\circ} \mathrm{C}$ & $29-33^{\circ} \mathrm{C}$ \\
\hline Time of stable climate & 600 & 800 \\
\hline Warming time & 600 & 600 \\
\hline Level of climate change & 1 and $2^{\circ} \mathrm{C} / 100$ years & 1 and $2^{\circ} \mathrm{C} / 100$ years \\
\hline Environmental stochasticity & $0{ }^{\circ} \mathrm{C}$ & $0.01,0.1,1^{\circ} \mathrm{C}$ \\
\hline Thermal gradient & $0.01^{\circ} \mathrm{C} /$ latitude & $0.01^{\circ} \mathrm{C} /$ latitude \\
\hline Number of latitude on the map & 1700 & 1700 \\
\hline Number of longitude on the map & 15 & 15 \\
\hline Replicate & 50 & 20 \\
\hline
\end{tabular}

841 Table 1: Summary of the model parameters and their values in the main simulations and in extra simulations performed for robustness analyses. 
Figures:

$845 \quad$ Figure 1
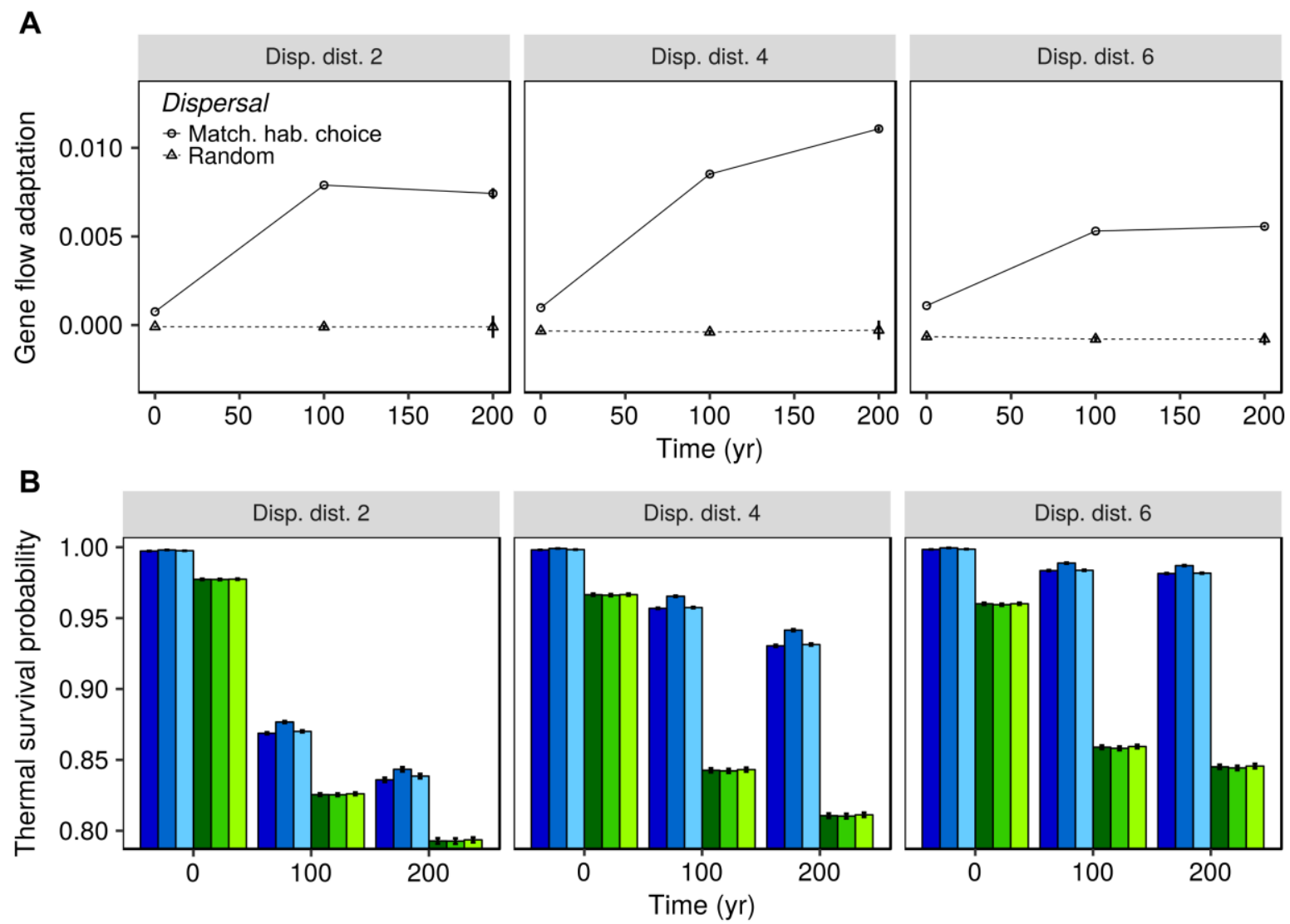

Dispersal $x$ status

Match. hab. $x$ emig.

Match. hab. $x$ immig.

Match. hab. $x$ resid.

Random $x$ emig.

$\square$ Random x immig.

Random $x$ resid. 
$848 \quad$ Figure 2
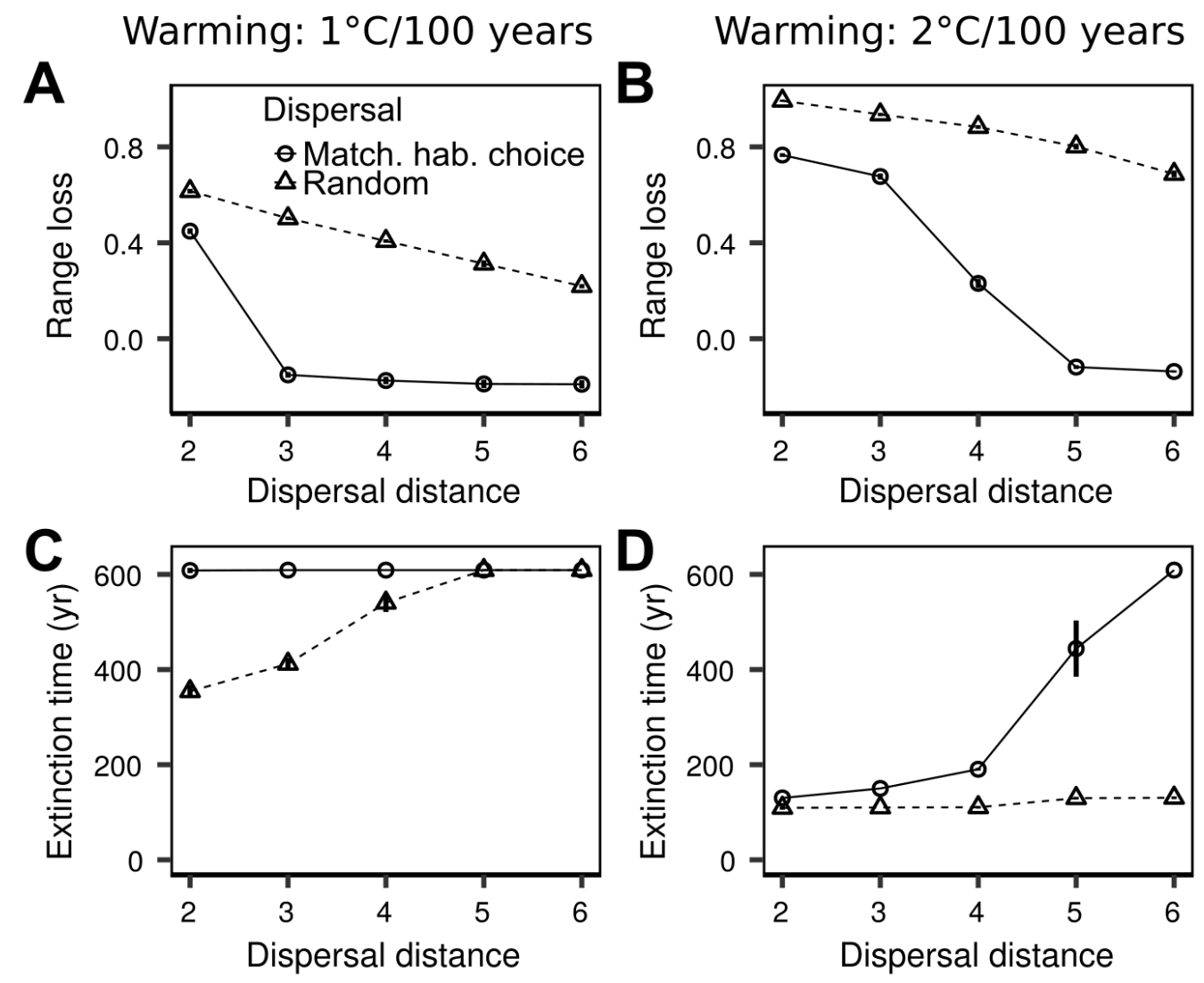

849 
Warming: $1^{\circ} \mathrm{C} / 100$ years Warming: $2^{\circ} \mathrm{C} / 100$ years
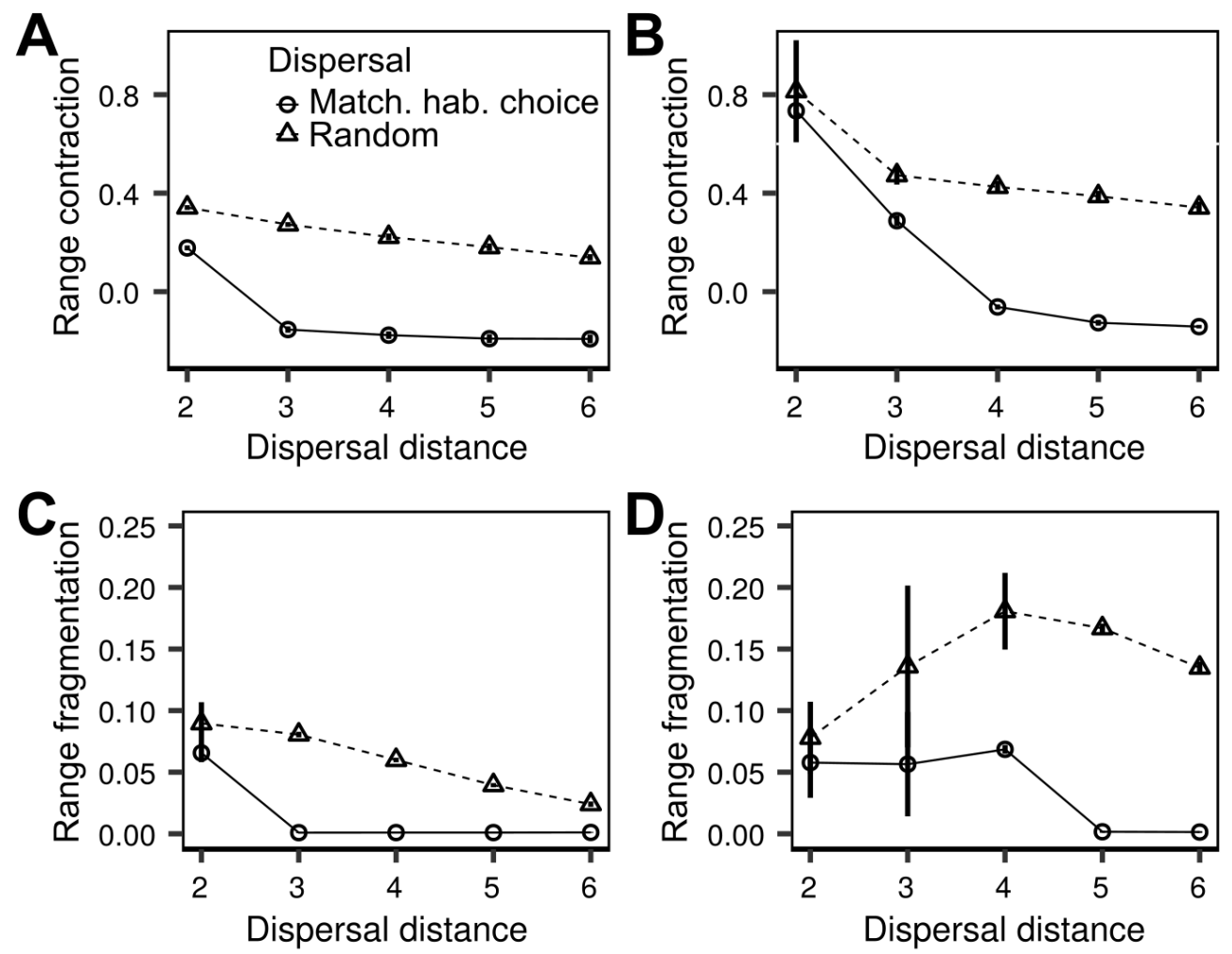

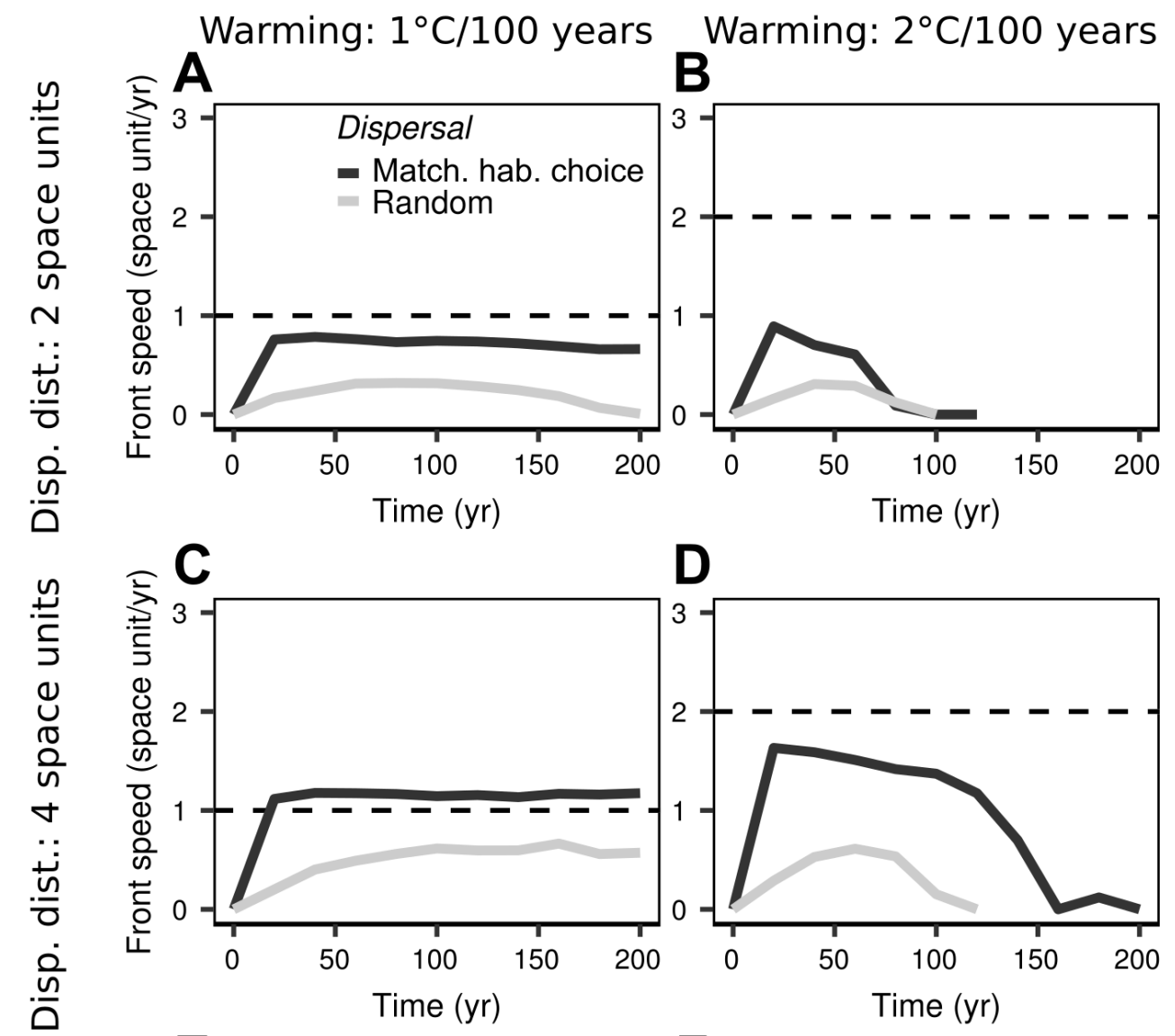

D
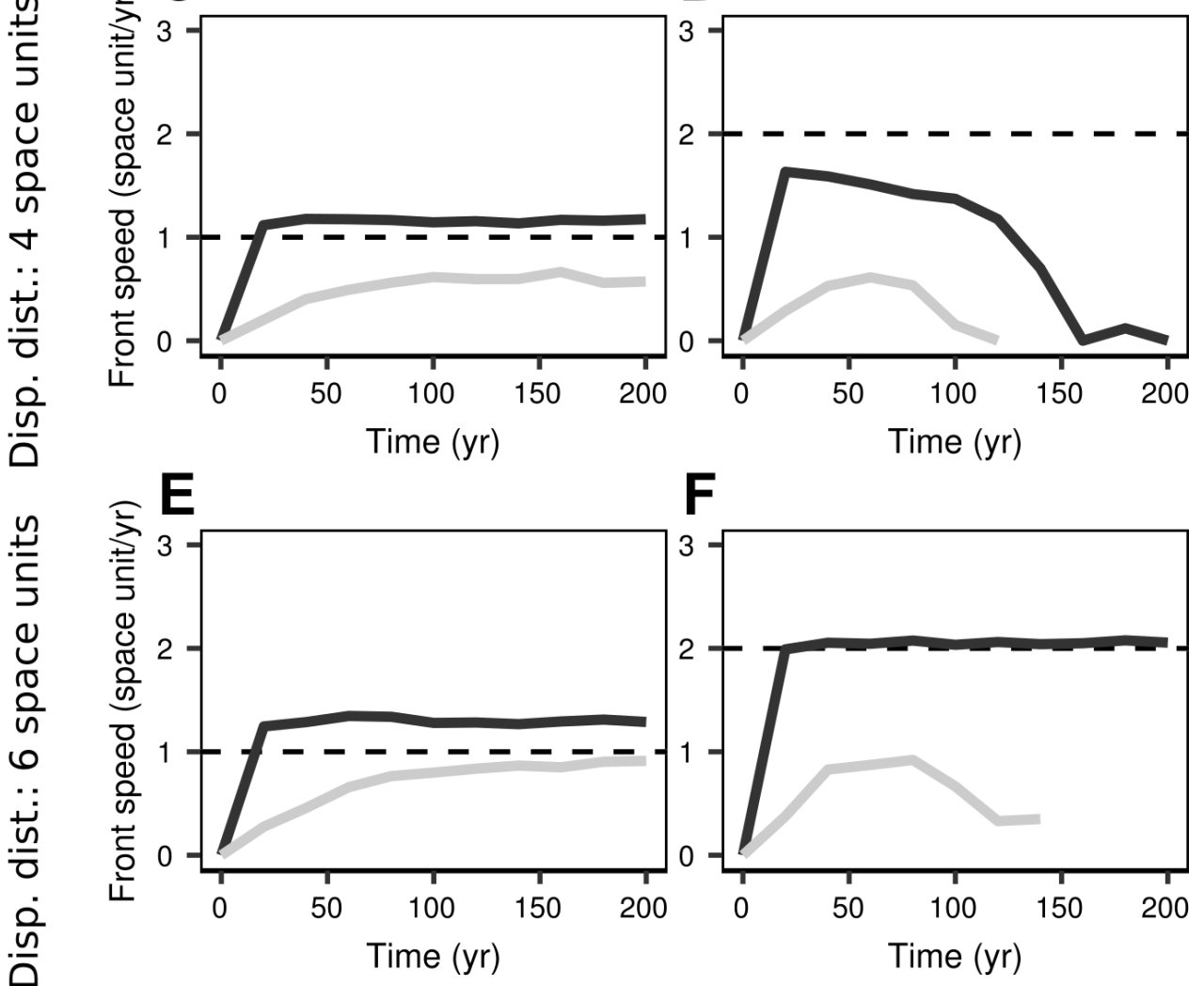

F

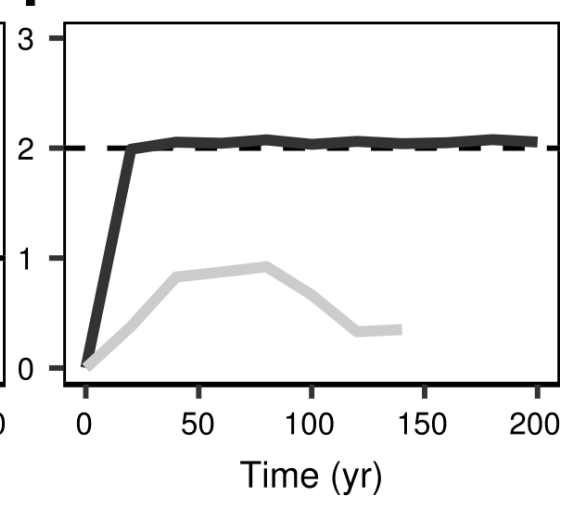



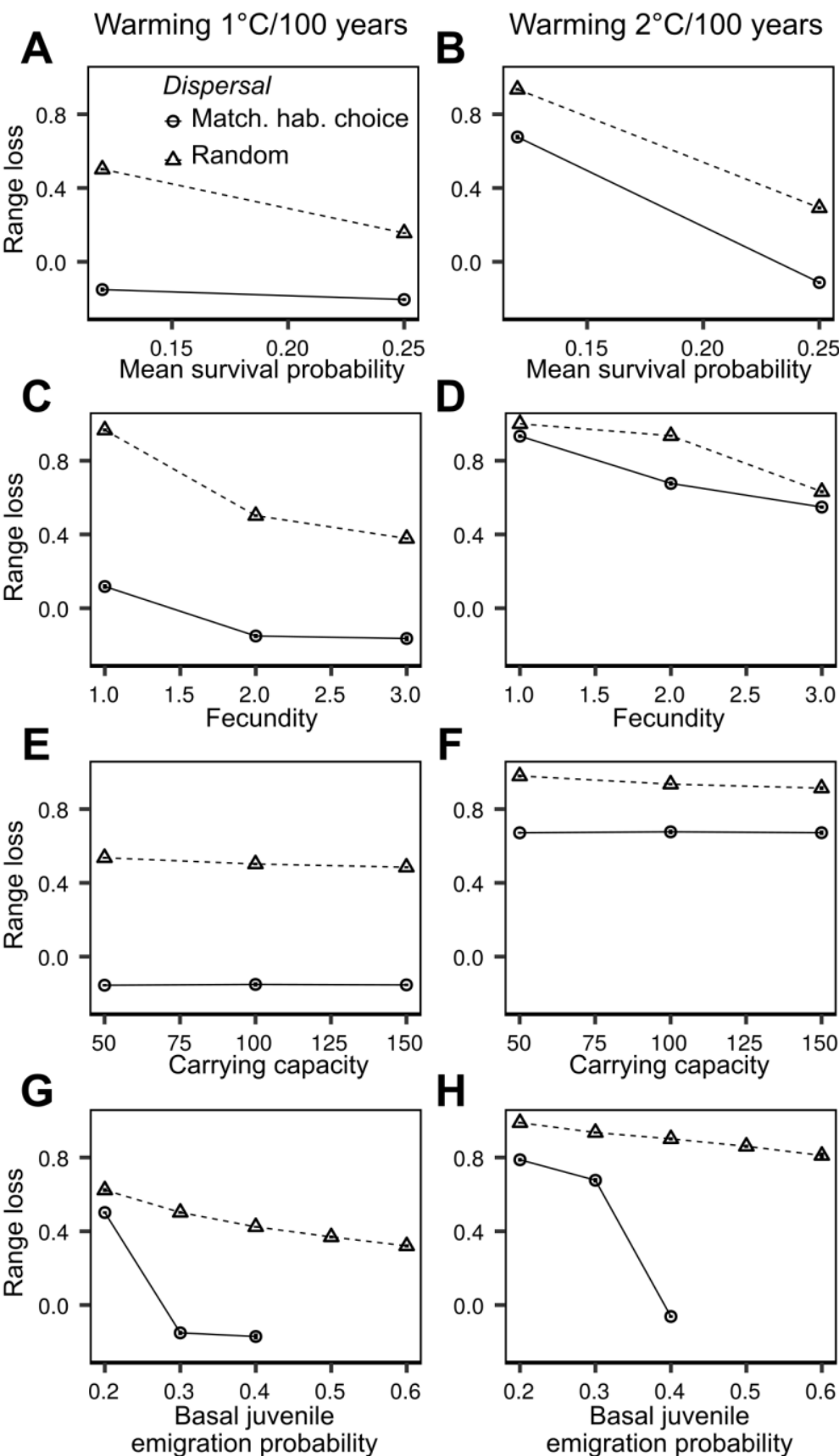
Warming $1^{\circ} \mathrm{C} / 100$ years

Warming $2^{\circ} \mathrm{C} / 100$ years

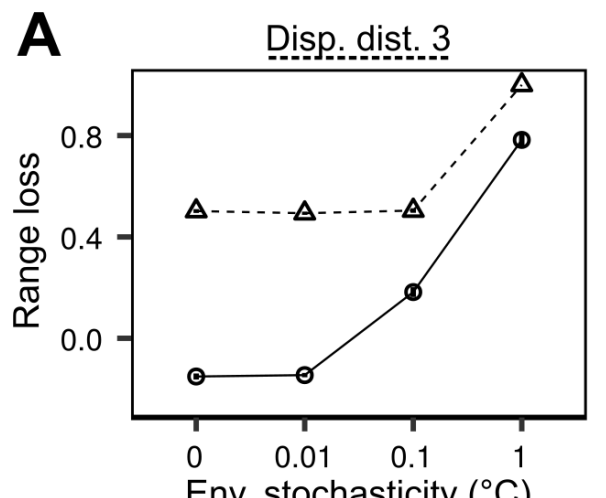

B

Disp. dist. 3

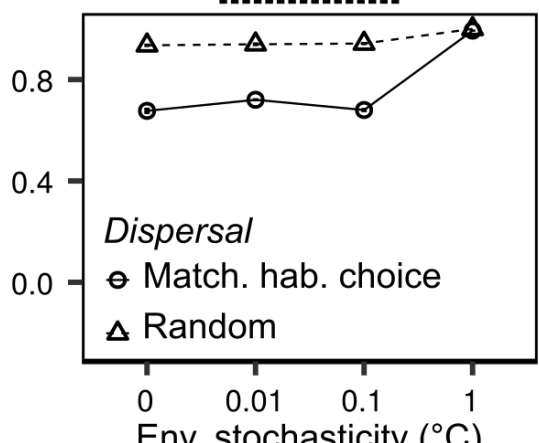

C

Env. stochasticity $\left({ }^{\circ} \mathrm{C}\right)$

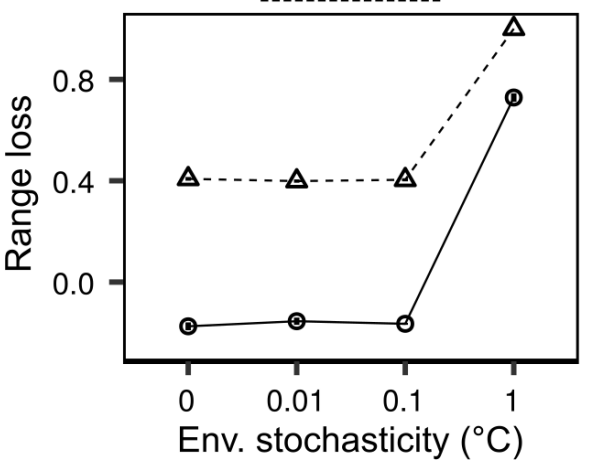

D Disp. dist. 4

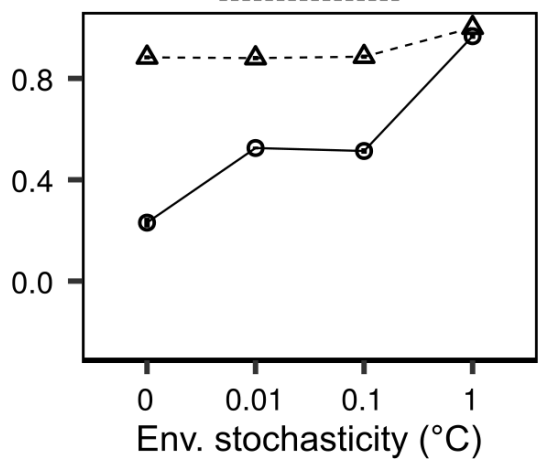

E

Disp. dist. 5

F

Dispp. dist. 5
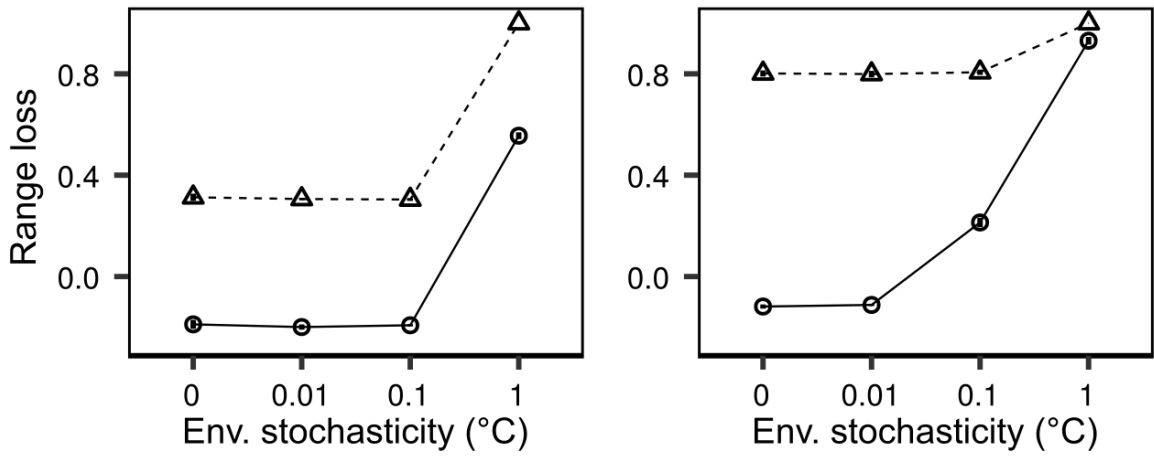